\title{
A Model of Tradeable Capital Tax Permits
}

\author{
By \\ Timothy Hubbard \\ and \\ Justin Svec \\ March 2014 \\ COLLEGE OF THE HOLY CROSS, DEPARTMENT OF ECONOMICS \\ FACULTY RESEARCH SERIES, PAPER NO. 12-02*

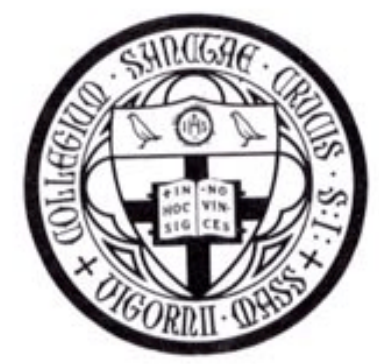 \\ Department of Economics \\ College of the Holy Cross \\ Box 45A \\ Worcester, Massachusetts 01610 \\ (508) 793-3362 (phone)
}

(508) 793-3708 (fax)

http://www.holycross.edu/departments/economics/website

*All papers in the Holy Cross Working Paper Series should be considered draft versions subject to future revision. Comments and suggestions are welcome. 


\title{
A Model of Tradeable Capital Tax Permits*
}

\author{
Timothy P. Hubbard ${ }^{\dagger}$ \\ Justin Svec
}

March 2014

\begin{abstract}
Standard models of horizontal capital tax competition predict that, in a Nash equilibrium, states set tax rates inefficiently due to externalities - capital inflow to one state corresponds to capital outflow for another state. Researchers often suggest that the federal government impose Pigouvian taxes to correct for these effects and achieve efficiency. We propose an alternative incentive-based regulation: tradeable capital tax permits. Under this system, the federal government would require a state to hold a permit if it wanted to reduce its capital income tax rate from some pre-defined benchmark. These permits would be tradeable across states. We show that, if the federal government sets the correct number of total permits, then social efficiency is achieved. We discuss the advantages of this system relative to the canonical suggestion of Pigouvian taxes.
\end{abstract}

JEL Classification: H25, H42, H70.

Keywords: tax competition; tradeable permits; asymmetric states.

${ }^{*}$ We thank Bryan Engelhardt, Gagan Ghosh, B. Ravikumar, Tom Tietenberg, and David E. Wildasin for helpful comments. We also appreciate constructive comments from two anonymous referees, an associate editor, and the editor, John P. Conley, who provided helpful suggestions which improved the manuscript.

${ }^{\dagger}$ Hubbard: Department of Economics, Colby College, 5242 Mayflower Hill, Waterville, ME 04901; email: timothy.hubbard@colby.edu; phone: 207-859-5242; fax: 207-859-5248.

${ }^{\ddagger}$ Svec: Department of Economics, College of the Holy Cross, Box 45A, Worcester, MA 01610; email: jsvec@holycross.edu; phone: 508-793-3875; fax: 508-793-3710. 


\section{Introduction}

One of the key insights in the tax competition literature is that policy competition across states leads to socially inefficient policy choices. The inefficiency is due to the presence of externalities, which can be particularly salient when considering a state's tax rate on a relatively mobile factor like capital. Specifically, if the states are sufficiently similar, then in its competition for scarce capital, each state has the incentive to cut its capital income tax rate. ${ }^{1}$ This reduction spurs an inflow of capital, raising wages, total tax revenues, and public-good provision. A capital inflow towards one state, though, means a capital outflow from other states. This outflow implies that other states will confront lower wages, a decreased tax base, and hence lower public-good provision. These welfare costs to other states are not internalized by the state considering a decrease in its capital income tax rate. Consequently, from a social perspective, each state sets an inefficient tax on capital income.

The responses of other states compound the problem: other, similarly-sized states respond by decreasing their own capital income tax rate, hoping to prevent the capital outflow. As such, the tax competition literature predicts a "race to the bottom" in which all states feel obliged to set suboptimally low tax rates on capital. One implication of this is that states must either increase other taxes (e.g., labor, consumption, property, etc.) to supplement lost capital tax revenue or decrease their provision of public goods.

A recent example of this incentive to poach other states' capital involves Illinois and Wisconsin. Due to its large debt, Illinois was recently forced to raise its tax rates on both personal and corporate income. The Wisconsin governor, Scott Walker, responded to this move, saying "Today we renew that call to Illinois businesses, 'Escape to Wisconsin.' You are welcome here." ${ }^{2}$ In support of this sentiment, the Wisconsin State Legislature passed a proposal that would eliminate the corporate income tax rate for two years for firms that relocate to Wisconsin from other states. ${ }^{3}$

In addition to this anecdote, there is evidence of tax competition at all levels of government.

\footnotetext{
${ }^{1}$ Bucovetsky (1991) shows that if the states are sufficiently asymmetric, the larger state (the capital importer) would want to raise its tax above the efficient level.

${ }^{2}$ See http://walker.wi.gov/journal_media_detail . asp?prid=5569\&locid=177.

${ }^{3}$ See Assembly Bill 3 in the January 2011 Special Session of the State of Wisconsin 2011-2012 Legislature available at http://legis.wisconsin.gov/2011/data/JR1AB-3.pdf.
} 
Slemrod (2004) noted that corporate tax rates across countries began declining in the 1980s and seemed to be converging, facts that are consistent with tax competition. While his goal was to disentangle competing arguments for whether this observation is, in fact, evidence of tax competition, he found measures of openness are negatively associated with corporate tax rates. Likewise, Devereux, Lockwood, and Redoano (2008) found evidence of strategic interaction between countries with open economies and concluded that reductions in tax rates can be explained almost entirely by more intense competition. Carlsen, Langset, and Ratts $\varnothing$ (2005) used data from Norway to construct a measure of firm mobility which they used to show that municipalities with high firm mobility tend to have lower tax levels. Davies (2005) provided evidence that U.S. states compete in offering incentives, often in the form of firm-specific tax reductions, to multinational enterprises in trying to attract foreign direct investment, which likely transfer rents from the states to the firms. Thus, the incentive for states to attract capital from other states by offering low capital tax rates seems both theoretically and empirically relevant.

The incentives driving one state to reduce its capital income tax rate in order to attract other states' capital (or protect the loss of its own capital) can be costly in terms of national welfare. In an international model with competing countries, Mendoza and Tesar (1998) predicted that if the U.S. eliminated its capital income tax rate, then Europe would face a decrease in welfare that is comparable to a $1.7 \%$ decline in trend consumption. This large welfare cost is due to the fact that Europe not only faces a capital outflow, but also must increase its tax on consumption in order to maintain fiscal solvency.

Many researchers have proposed ways to solve the tax competition problem. These solutions fall into two categories. The first type of solution calls on all states to jointly increase their tax rates; see, for example, Batina (2009). This suggestion would give the states the chance to escape the less-efficient Nash equilibrium. The difficulty, of course, is that the agreement is not incentive compatible - each state would have the incentive to cheat on the agreement by reducing its capital income tax to attract other states' capital. Because of this, the agreement to jointly increase tax rates can only be supported with costly monitoring and enforcement. Alternatively, modeling the game as one that involves repeated interactions between governments can allow standard results 
from dynamic game theory to hold. For example, if governments are sufficiently patient, the socially optimal equilibrium can be achieved in an infinitely-repeated game. Interestingly, Cardarelli, Taugourdeau, and Vidal (2002) showed that such results need to be qualified in the presence of asymmetries: if states are sufficiently asymmetric with respect to endowment (or marginal valuation of the public good), the only way to achieve fiscal policy harmonization is through the creation of a central fiscal authority.

The second type of solution proposes that the federal government imposes a (state-specific) Pigouvian tax on states that reduce their capital tax rates; see, for example, Wildasin (1989) as well as DePeter and Myers (1994). ${ }^{4}$ If the taxes are set correctly, the benefit of this approach is that each state fully internalizes the social cost of modifying its tax rate. Consequently, all states choose the socially efficient level of capital taxes. A disadvantage of this solution is informational: it is difficult for the federal government to acquire the requisite information to determine the efficient values of the Pigouvian tax for each state. This problem is made more severe by the fact that each state has the incentive to deceive the federal government about its characteristics in the hope of influencing its Pigouvian tax.

In this paper, we propose an alternative solution which, like the Pigouvian tax, induces the states to internalize the externality associated with their actions, while simultaneously reducing the informational burden imposed on the federal government. Specifically, we consider establishing a market for capital income tax reduction permits, where a permit is defined as the right to reduce a state's capital income tax rate from a benchmark value by one percentage point for some specified period of time. ${ }^{5}$ With this market in place, the number of permits a state holds determines how much the state can decrease its capital income tax rate from its benchmark. A public exchange would allow states that wanted to lower their capital tax rate to purchase permits from other states, whose capital tax rates would necessarily rise in response. Importantly, we show that if the total number of permits is set correctly, the market price of the permits reflects the size of

\footnotetext{
${ }^{4}$ Peralta and van Ypersele (2006) proposed a reform consisting of the design of a tax range as an alternative to full harmonization.

${ }^{5}$ We have decided to apply this market solution to capital income tax rates, but there is no reason why the idea should be limited to just this type of tax competition. Indeed, the idea could apply to any fiscal instrument that causes an externality in another state, including the labor income tax rate and spending on public assistance programs.
} 
the externality associated with reducing an individual state's capital income tax rate. Each state then fully internalizes the social cost of its action since purchasing (holding) a permit is costly (involves an opportunity cost). As such, the permit system induces states to choose to implement the socially efficient capital income tax rates.

While our application is new, the benefits of tradeable permits have been well studied in other settings within the fields of environmental economics and auctions. We borrow insights from the environmental economics literature where permits represent the right to emit a unit of pollution. The establishment of the U.S. market for tradeable sulfur dioxide $\left(\mathrm{SO}_{2}\right)$ emissions permits in Title IV of the 1990 Clean Air Act Amendments was considered the first large-scale environmental program to rely on private markets. The main features of the program and early documentations of the program's success were described by Joskow, Schmalensee, and Bailey (1998), among others. Joskow et al. argued that a relatively efficient market price for permits was achieved after just a few years - something that is quite remarkable when taking into consideration the number of facilities that emit $\mathrm{SO}_{2}$ in the country. In contrast, the setting we study is simpler in that the players (decision makers) are clearly defined to be the states' governing bodies. Such transparency could allow for efficiency even quicker.

Our application is perhaps closest in spirit to that of Casella (1999) who proposed the use of marketable permits as a way of achieving deficit spending goals of the Pact for Stability and Growth (Stability Pact) in the European Monetary Union (EMU). The Stability Pact suggested a ceiling for each member country's deficit spending of 3\% of its GDP. Casella emphasized practical disadvantages and weaknesses of the proposed deficit ceiling and suggested how they could be addressed in a more flexible system of tradeable deficit permits. ${ }^{6}$ A virtue of her suggestion is that it not only aligns countries' incentives with those of the EMU, but also that it allows countryspecific idiosyncratic shocks to be smoothed by the acquisition or sale of permits. This feature holds in our application as well if public goods expenditures can substitute for fluctuations in other areas of the economic system. While her work is primarily argumentative in nature, we formalize the mechanism in the context of horizontal tax competition by providing and working within a

\footnotetext{
${ }^{6}$ Breuillé (2007) considers tradeable deficit permits in an dynamic setting and shows that efficiency obtains if the permits can be traded through time (i.e., permits can be bought, sold, banked, or borrowed).
} 
specific modeling framework.

Our paper is structured as follows: in Section 2, we present a model in which potentially asymmetric states compete for scarce capital by adjusting their capital income tax rates. We derive the optimal tax rates that emerge when states act competitively and when a social planner can choose all states' tax rates. Given these equilibria, we document the inefficiency that occurs when states set tax policy competitively. In Section 3, we propose our solution to the inefficiency created by tax competition. Upon formalizing the market for permits, we show that each state has the incentive to choose the socially efficient capital tax rate, as long as the cap on total permits is set correctly. We also show that the federal government can induce participation in the permits system from all states and that, even if the aggregate number of permits is set inefficiently, the permits system preserves some attractive social welfare features. We conclude in Section 4.

\section{Model}

Consider a model of capital tax competition as presented originally by Zodrow and Mieszkowski (1986) and made asymmetric by Bucovetsky (1991) and Wilson (1991). Specifically, a country is divided into two, possibly asymmetric, states. In each state, capital and labor are used to produce a single, homogenous good according to the per-capita production function $f\left(k_{i}\right)$, where $k_{i}$ is the per-capita capital stock in state $i \in\{1,2\}$. The homogenous good's price is set to one. Assume the production function is concave in $k_{i}$, twice continuously differentiable, and exhibits constant returns-to-scale in capital and labor. ${ }^{7}$ The factor markets are perfectly competitive. Let $w_{i}$ and $r_{i}$ be the wage rate and the net return on capital, respectively, in state $i$. The gross return on capital in state $i$ is then $f^{\prime}\left(k_{i}\right)$, and the wage is

$$
w_{i}=f\left(k_{i}\right)-f^{\prime}\left(k_{i}\right) k_{i} .
$$

\footnotetext{
${ }^{7}$ We also assume the Inada conditions $\left(f^{\prime}(0)=\infty, f^{\prime}(\infty)=0\right), f(0)=0$ and $f^{\prime \prime}(k)$ is finite for finite and non-zero values of $k$.
} 
Likewise, the net return on capital is

$$
r_{i}=f^{\prime}\left(k_{i}\right)-t_{i}
$$

where $t_{i}$ corresponds to the capital income tax rate in state $i$. We assume that state $i$ 's tax rate is such that $r_{i}>0 .^{8}$

We consider capital to be perfectly mobile across states, while labor is immobile. The former assumption implies that, in equilibrium, the after-tax rate-of-return on capital is equal across states:

$$
r \equiv f^{\prime}\left(k_{1}\right)-t_{1}=f^{\prime}\left(k_{2}\right)-t_{2} .
$$

Further, the nation's capital-labor ratio is fixed at $k^{*}$. It can be shown that $k^{*}$ is equal to a weighted average of each state's capital-labor ratio:

$$
k^{*}=s_{1} k_{1}+s_{2} k_{2}
$$

where $s_{i}=\frac{L_{i}}{L_{1}+L_{2}}$ represents the population share of state $i$. Researchers concerned with horizontal tax competition have introduced asymmetries in a variety of ways. These asymmetries all lead to the same result - certain states will want to set lower taxes than other states. We consider asymmetric populations. As will be clear, states with smaller populations have incentive to set lower taxes than states with larger populations. Our findings concerning the permits mechanism would apply to other asymmetries as well.

Output can be consumed either as a private good, $x$, or as a public good, $g$. Consumers derive utility from both of these goods. We assume that the utility function is quasilinear in private and public consumption

$$
u\left(x_{i}, g_{i}\right)=v\left(x_{i}\right)+g_{i}
$$

This assumption, while limiting, is necessary for the proof of Theorem 1 in Section 3. Consumers

\footnotetext{
${ }^{8}$ Bucovetsky (1991) provided a detailed characterization of the "excess supply" regime in which $r_{i}=0$. His results apply to our setting too, although we do not present them formally as the supply of capital in one state is independent of that of other states in such cases and so the incentive effects we seek to highlight are no longer relevant. Moreover, Bucovetsky showed that, under fairly mild assumptions, equilibria with excess supply of capital can be ruled out-see Lemmata 3 and 4 of his paper. Wilson (1991) also choose to neglect the "empirically irrelevant" case where $r_{i}=0$.
} 
purchase the private good using their income, which is composed of labor and capital income. Assuming that each consumer inelastically supplies one unit of labor, a consumer's labor income is equal to the wage. We also assume that each consumer holds an equal share of the nation's capital stock so that a representative consumer's capital income is then $r k^{*}$. As there is no saving in the model, the consumers spend all of their income on the private good:

$$
x_{i}=w_{i}+r k^{*}=f\left(k_{i}\right)-f^{\prime}\left(k_{i}\right) k_{i}+r k^{*}
$$

where we make implicit use of the fact that the output good is the numéraire good.

The provision of the public good is funded by each state government's capital tax revenues. Given that state $i$ 's tax $t_{i}$ applies to all capital employed in state $i$, tax revenues are $t_{i} k_{i}$. Consequently, each government's budget constraint is

$$
g_{i}=t_{i} k_{i}
$$

We assume that each state government is benevolent and seeks to maximize the utility of the consumers who live in that state.

\subsection{The Competitive Equilibrium}

Suppose that both state governments set their capital tax rates in a non-cooperative fashion, taking the other state's tax as given. ${ }^{9}$ The optimization problem for state $i$ 's government, then, is

$$
\max _{t_{i}} v\left(x_{i}\right)+g_{i}
$$

subject to (1)-(4).

To simplify this problem, note that for a given pair of tax rates $\left(t_{i}, t_{j}\right)$, the capital-labor ratio

\footnotetext{
${ }^{9}$ Non-cooperative solutions were considered for commodity taxes by Mintz and Tulkens (1986) as well as de Crombrugghe and Tulkens (1990). Wildasin (1988) compared equilibria of two types of seemingly similar fiscal competition games: one in which governments choose the tax rate on mobile capital and one in which governments choose a level of public expenditures. He found the two equilibria, in general, do not coincide even in symmetric models (where states or jurisdictions are identical) and that equilibria in expenditures entail more intense rivalry and result in lower levels of public good provision; thus, larger inefficiencies obtain in such settings.
} 
in each state is determined by (1) and (2). Call the resulting capital-labor ratio $k_{i}\left(t_{i}, t_{j}\right)$. We can use this result to analyze how the capital-labor ratio moves with respect to the tax rate. Given that the national capital-labor ratio is fixed, it is straightforward to show that

$$
\frac{\partial k_{i}}{\partial t_{i}}=\frac{s_{j}}{s_{j} f^{\prime \prime}\left(k_{i}\right)+s_{i} f^{\prime \prime}\left(k_{j}\right)}<0
$$

where the inequality holds because of the concavity of the production function. This equation suggests that there is a capital inflow (outflow) when state $i$ lowers (raises) its tax rate. Furthermore, the sensitivity of capital to the tax rate depends on the relative size of the state: as the population share of a state rises, the capital-labor ratio in that state becomes increasingly insensitive to tax changes. This suggests, as in Bucovetsky (1991), that large states face less incentive to reduce their tax rates in order to attract capital than do small states, a characteristic that will become important in the permits model below.

Using the fact that the capital-labor ratio can be written as a function of the pair of tax rates, we can also solve for the wage, the after-tax rate of return on capital, private good consumption, and public good consumption as functions of the tax rates. Call these values $w_{i}\left(t_{i}, t_{j}\right), r_{i}\left(t_{i}, t_{j}\right)$, $x_{i}\left(t_{i}, t_{j}\right)$, and $g_{i}\left(t_{i}, t_{j}\right)$, respectively. Since $w_{i}\left(t_{i}, t_{j}\right)$ and $r\left(t_{i}, t_{j}\right)$ both fall with an increase in $t_{i}$, we know that $\frac{\partial x_{i}}{\partial t_{i}}<0$.

With these findings, we can now more fully understand the externality associated with capital tax competition. The government in state $i$ has the incentive to reduce its tax rate in order to attract capital. This action increases the wage and the private good consumption of that state's consumers. However, the decrease in the tax rate induces an outflow of capital from state $j$ which reduces the wage and private good consumption of that state. When state $i$ makes the decision to lower its tax rate, it does not internalize the harm that comes to state $j$ 's citizens. Consequently, state $i$ chooses an inefficiently low capital tax rate.

As noted earlier, the optimal, non-cooperative tax rate set by the government in state $i$ solves 
the following optimization problem:

$$
\max _{t_{i}} v\left[x_{i}\left(t_{i}, t_{j}\right)\right]+g_{i}\left(t_{i}, t_{j}\right)
$$

subject to (1)-(4). The first-order condition of this maximization problem is

$$
v^{\prime}\left(x_{i}\right) \frac{\partial x_{i}}{\partial t_{i}}+\frac{\partial g_{i}}{\partial t_{i}}=0
$$

where

$$
\frac{\partial x_{i}}{\partial t_{i}}=f^{\prime \prime}\left(k_{i}\right) \frac{\partial k_{i}}{\partial t_{i}}\left[k^{*}-k_{i}\right]-k^{*}
$$

and

$$
\frac{\partial g_{i}}{\partial t_{i}}=k_{i}+t_{i} \frac{\partial k_{i}}{\partial t_{i}}=k_{i}\left(1+\frac{\partial k_{i}}{\partial t_{i}} \frac{t_{i}}{k_{i}}\right)
$$

Note that $\frac{\partial x_{i}}{\partial t_{i}}<0$ as we showed above, while the sign of $\frac{\partial g_{i}}{\partial t_{i}}$ depends on the elasticity of the capital inflow to a state with respect to the state's tax rate. ${ }^{10}$ By combining both states' first-order conditions, we can derive the Nash equilibrium pair of tax rates, $\left(t_{1}^{*}, t_{2}^{*}\right)$. At these tax rates, $\frac{\partial g_{i}}{\partial t_{i}}>0$, meaning that each state is on the increasing side of the Laffer curve. Intuitively, these competitive equilibrium tax rates obtain where the marginal cost and marginal benefit of each state modifying its capital tax rate are equal to each other, given the tax rate set by the rival state. The marginal cost of state $i$ raising its tax is that capital will flood out, reducing private consumption. The value of this loss is $v^{\prime}\left(x_{i}\right) \frac{\partial x_{i}}{\partial t_{i}}$. The marginal benefit of raising the tax is that public consumption increases, which is valued at $\frac{\partial g_{i}}{\partial t_{i}}$.

It has been proven theoretically by Bucovetsky (1991) and Wilson (1991), and extended to many states by Peralta and van Ypersele (2005), that if the populations of the two states are different, the smaller state chooses the lower capital tax rate in equilibrium. This is because the elasticity of capital with respect to the tax rate, which is always negative, becomes more negative as that state's population share falls. The smaller state therefore has more elastic demand for capital and chooses to set its tax rate lower than the large rival state, encouraging a greater rise in its

\footnotetext{
${ }^{10}$ Indeed, $\frac{\partial x_{i}}{\partial t_{i}}<0$ even though $\left[k^{*}-k_{i}\right]$ may be positive or negative since $f^{\prime \prime}\left(k_{i}\right) \frac{\partial k_{i}}{\partial t_{i}} \leq 1$.
} 
capital-labor ratio.

\subsection{The First-Best Solution}

Suppose instead that a federal government could set each state's capital tax rate. The federal government's maximization problem, then, is to choose the pair of tax rates that maximizes the sum of the population-weighted state utilities. Note that, since each state's consumers' utility enters its objective, the federal government will account for the externality associated with tax competition; that is, the resulting tax rates, $\left(t_{1}^{F B}, t_{2}^{F B}\right)$, are socially efficient.

In deriving the first-best solution, rather than choose the capital tax rates, important insights can be seen by considering the decision variables $g_{1}, g_{2}, x_{1}, x_{2}, k_{1}$, and $k_{2}$ directly. These are all functions of the pair of tax rates $\left(t_{1}, t_{2}\right)$. Consider the following optimization problem, for which $k_{2}$ has been replaced by $\left(k^{*}-s_{1} k_{1}\right) / s_{2}$ given equation $(2)$ :

$$
\begin{aligned}
\max _{\left\{x_{1}, g_{1}, x_{2}, g_{2}, k_{1}\right\}} \mathcal{L}=s_{1}\left[v\left(x_{1}\right)\right. & \left.+g_{1}\right]+s_{2}\left[v\left(x_{2}\right)+g_{2}\right] \\
+\lambda & {\left[s_{1} f\left(k_{1}\right)+s_{2} f\left(\frac{k^{*}-s_{1} k_{1}}{s_{2}}\right)-s_{1} x_{1}-s_{1} g_{1}-s_{2} x_{2}-s_{2} g_{2}\right] . }
\end{aligned}
$$

The first-order conditions are

$$
\begin{aligned}
& \frac{\partial \mathcal{L}}{\partial g_{1}}=s_{1}-\lambda s_{1}=0 \\
& \frac{\partial \mathcal{L}}{\partial g_{2}}=s_{2}-\lambda s_{2}=0 \\
& \frac{\partial \mathcal{L}}{\partial x_{1}}=s_{1} v^{\prime}\left(x_{1}\right)-\lambda s_{1}=0 \\
& \frac{\partial \mathcal{L}}{\partial x_{2}}=s_{2} v^{\prime}\left(x_{2}\right)-\lambda s_{2}=0 \\
& \frac{\partial \mathcal{L}}{\partial k_{1}}=\lambda\left[s_{1} f^{\prime}\left(k_{1}\right)-s_{2} \frac{s_{1}}{s_{2}} f^{\prime}\left(k_{2}\right)\right]=0 .
\end{aligned}
$$

These conditions make clear two things: first, the Samuelson rule for optimal provision of a public good holds; second, the capital-labor ratios are equalized across states. This latter means that, in order to achieve the first-best solution through decentralized taxes, the following claim must be 
true:

Claim 1. In the socially efficient (first-best) equilibrium, both states set the same capital tax rate (tax harmonization occurs), regardless of their populations shares. This optimal tax rate, $t$, solves the equation $v^{\prime}\left(f\left(k^{*}\right)-t k^{*}\right)=1$.

Proof. From the first two first-order conditions, we see that $\lambda=1$. Plugging this result into the final first-order condition, we get that $f^{\prime}\left(k_{1}\right)=f^{\prime}\left(k_{2}\right)$, which holds regardless of the states' population shares. Since both states share the same production technology, this condition implies that $k_{1}=k_{2}$. Thus, the planner finds it optimal to equate all states' marginal products of capital by setting their capital-labor ratios equal to each other. To achieve this solution using the fiscal tools available to the states, equation (1) implies the planner must equate all states' tax rates, leading to the tax harmonization mentioned in the proposition. The final point that we must prove is that the efficient tax rate solves the equation: $v^{\prime}\left(f\left(k^{*}\right)-t k^{*}\right)=1$. To show that this is the case, examine the first-order conditions with respect to each state's private consumption good. Those conditions imply that $v^{\prime}\left(x_{i}\right)=1$ for $i \in\{1,2\}$. Plugging (3) into this condition, we get that $v^{\prime}\left(f\left(k_{i}\right)-f^{\prime}\left(k_{i}\right) k_{i}+r k^{*}\right)=v^{\prime}\left(f\left(k_{i}\right)-f^{\prime}\left(k_{i}\right) k_{i}+\left[f^{\prime}\left(k_{i}\right)-t\right] k^{*}\right)=v^{\prime}\left(f\left(k^{*}\right)-t k^{*}\right)$, where the last equality comes from the fact that $k_{i}=k^{*}$ for $i \in\{1,2\}$. This then completes the proof of the claim.

As this result makes clear, the planner equates all states' taxes in order to ensure that the states' marginal products of capital are equal. If this were not the case, the planner could transfer capital from the state with the low marginal product to the state with the high marginal product, an action that would raise aggregate welfare. This increase would be realized for two reasons: first, because of the curvature in the production function, this capital movement would raise aggregate production; second, because of the curvature of the consumers' utility functions, the utility loss of the consumers in the low marginal product state would be smaller than the utility gain of the consumers in the high marginal product state. As such, the planner finds it optimal to keep moving capital until all states' marginal products of capital are equal.

A second key piece of intuition from this optimization problem is that the planner internalizes 
the externality associated with horizontal tax competition and so chooses a different set of taxes than found in the Nash equilibrium. When the federal government considers a rise in state $i$ 's tax rate, it perceives the same marginal cost as did that state in the competitive equilibrium: a rise in the tax rate induces an outflow of capital, which lowers private consumption. However, the federal government perceives the marginal benefit to be higher than in the competitive equilibrium. This is because the rise in state $i$ 's tax rate leads to an increase in the capital-labor ratio of state $j$, a benefit not valued by state $i$ in the competitive equilibrium which involves each state equating its private marginal benefit with its private marginal cost. The socially-efficient capital taxes involve the planner equating the marginal social benefit with the marginal social cost, leading to capital taxes that differ from those in the Nash equilibrium - a result that has been shown consistently in the horizontal tax competition literature. ${ }^{11}$

\section{Model with Permits}

Until now we have simply shown that tax competition leads states to implement socially inefficient capital taxes. Two solutions to this inefficiency have been suggested by the tax competition literature: the states should agree to jointly change their tax rates to their efficient levels or the federal government should impose state-specific Pigouvian taxes on each state. In this section, we introduce an alternative: the creation of a capital tax permits market, where a permit is defined as the right to reduce a state's capital tax rate by one percentage point from a benchmark value, taking into account the state's population share. The permits can be sold on a public exchange, populated by state governments. The total number of permits created, the initial distribution of those permits, and the benchmark tax rates are to be set by the federal government. As we will show below, if the federal government supplies the correct number of permits given the benchmark,

\footnotetext{
${ }^{11}$ The public good is under-provided if $v^{\prime}\left(x_{i}\right)<1$ in equilibrium, or $\partial g_{i} / \partial t_{i}<-\partial x_{i} / \partial t_{i}$. This is always the case for the capital-exporting state since

$$
\left(1-f^{\prime \prime}\left(k_{i}\right) \frac{d k_{i}}{d t_{i}}\right)\left(k^{*}-k_{i}\right)>t \frac{d k_{i}}{d t_{i}}
$$

holds at the Nash equilibrium $k_{i}$ (the right-hand side of the inequality is negative while the left-hand side is positive). This need not hold for the capital-importing state but, since neither state is generically respecting the Samuelson rule, the public good is still mis-provided in the inefficient Nash equilibrium.
} 
the resulting price of the permits will fully reflect the size of the externality associated with capital tax competition and the socially efficient outcome will be realized. We characterize this equilibrium in the first subsection and then, in the second subsection, discuss some practical issues.

\subsection{Equilibrium}

Let $\left\{b_{1}, b_{2}\right\}$ be the benchmark pair of tax rates set by the federal government. These can take any value greater than the socially optimal tax rate and may or may not differ across states; i.e., the benchmark values can be arbitrary functions of population or be set uniformly. Let $\left\{q_{1}^{0}, q_{2}^{0}\right\}$ be the initial distribution of permits across the states, where $Q=\sum_{i=1}^{2} q_{i}^{0}$. Denote the price of a permit by $p$ and assume there are no terms-of-trade effects; that is, in choosing its optimal policy concerning a given state's capital tax rate, the state government does not consider how the price of a permit might change in response to its permit demand-it takes $p$ as given. ${ }^{12}$ After all transactions are finished, the final distribution of permits across states is $\left\{q_{1}^{P}, q_{2}^{P}\right\}$. Each permit held by state government $i$ allows that government to reduce its capital tax by one normalized percentage point; that is, one percentage point per percentage point in population share of that state. That is, if state $i$ wants to reduce its tax rate to $t_{i}$ from its benchmark, then it would need to hold $q_{i}=\frac{b_{i}-t_{i}}{s_{i}}$ permits. Notice, for the same percentage point drop in the capital tax, large states are required to hold fewer permits than small states. The intuition behind this result is seen in the competitive equilibrium: small states have more incentive to reduce their tax rates, and in order to deter this behavior, small states are forced to hold more permits. ${ }^{13}$ This is an attractive benefit of introducing

\footnotetext{
${ }^{12}$ We follow up on this assumption in Subsection 3.2.2 below.

${ }^{13}$ This result is analogous to the case of permits for pollution emissions that do not mix uniformly in the atmosphere (for example, this is true for $\mathrm{SO}_{2}$ pollution). To account for the fact that changes in the policy of one state do not affect the rival state in the same way, transfer coefficients are needed to link tax reductions with the external damages that result. One solution proposed in the environmental literature has been zonal permit systems which, in our case, would allow one-for-one trading of permits among states with similar population and would require states with sufficiently different characteristics to trade at a rate that accounts for a factor different from one; see, for example, Tietenberg (1995) for a discussion of these and other related issues concerning tradeable emissions permits. This would help mitigate, again borrowing from the environmental literature, the so-called "hot-spot" problem related to the fact that certain regions pool pollution more than others and so they bear an excessive share of the welfare burden from pollution. In our capital tax setting, this problem would arise when one state acquires a disproportionately large share of the existing permits. Note the difference however, in our setting the driving feature is incentives: certain states have incentive to reduce tax rates more than others; while in the pollution setting, exogenous factors play a roleenvironmental conditions lead to some unfortunate regions incurring a relatively large cost of the pollution externality. Furthermore, a distinction between zonal trading of pollution permits and that of our capital tax reduction permits is
} 
the asymmetry via state populations in that it leads to a particularly intuitive and simple rule that determines how many permits a state must hold to reduce its tax rate by a percentage point.

With the introduction of the public exchange, state government $i$ 's budget constraint becomes

$$
g_{i}=t_{i} k_{i}+p\left(q_{i}^{0}-q_{i}\right)
$$

where the second term on the right accounts for the fact that government revenue is a function of the number of permits bought or sold on the exchange. If $q_{i}<q_{i}^{0}$, then state $i$ has sold permits on the market and uses these additional funds to increase its spending on public goods. This increase in public good provision helps defray the cost of maintaining a higher tax rate on capital. If $q_{i}>q_{i}^{0}$, then state $i$ must purchase additional permits, which decreases its provision of public goods. This additional cost reflects the externality that decreasing the state's capital tax has on rival states. Finally, the market-clearing condition for permits is

$$
Q=\frac{b_{1}-t_{1}}{s_{1}}+\frac{b_{2}-t_{2}}{s_{2}}
$$

This market for permits does not affect the representative consumer directly, and so her utility function and budget constraint remain the same as before. Furthermore, the mobility of capital still ensures that (1) holds. Combining this equilibrium condition with (2), we can derive the distribution of capital across states as a function of the pair of tax rates: $k_{i}\left(t_{i}, t_{j}\right)$. Given this, the optimization problem for state $i$ is

$$
\max _{t_{i}} v\left[x_{i}\left(t_{i}, t_{j}\right)\right]+g_{i}\left(t_{i}, t_{j}\right)
$$

that the exchange rate in the latter case (and, in particular, in our model) is based on observable features of the states (such as population) whereas with pollution permits such transfer coefficients must be estimated or approximated based off how emissions in one region affect an area of interest. 
where

$$
\begin{aligned}
& g_{i}\left(t_{i}, t_{j}\right)=t_{i} k_{i}\left(t_{i}, t_{j}\right)+p\left(q_{i}^{0}-\frac{b_{i}-t_{i}}{s_{i}}\right) \\
& x_{i}\left(t_{i}, t_{j}\right)=f\left[k_{i}\left(t_{i}, t_{j}\right)\right]-f^{\prime}\left[k_{i}\left(t_{i}, t_{j}\right)\right] k_{i}\left(t_{i}, t_{j}\right)+\left\{f^{\prime}\left[k_{i}\left(t_{i}, t_{j}\right)\right]-t_{i}\right\} k^{*}
\end{aligned}
$$

The first-order condition from this problem is

$$
v^{\prime}\left(x_{i}\right) \frac{\partial x_{i}}{\partial t_{i}}+\frac{\partial g_{i}}{\partial t_{i}}=0
$$

where $\frac{\partial x_{i}}{\partial t_{i}}$ is the same as in (5) and

$$
\frac{\partial g_{i}}{\partial t_{i}}=k_{i}+t_{i} \frac{\partial k_{i}}{\partial t_{i}}+\frac{p}{s_{i}}
$$

The Nash equilibrium that results from the permit market satisfies the pair of first-order conditions embedded in (8) as well as the permit market-clearing condition (7). From these, and using what we know from the first-best solution, we can establish the following theorem:

Theorem 1. Given benchmarks $\left\{b_{1}, b_{2}\right\}$, if the two states have identical quasilinear utility functions and if their production functions are twice differentiable, the equilibrium tax rates that emerge from the permits market are the same as those in the socially efficient equilibrium, as long as the aggregate level of permits $Q$ is chosen correctly. As such, the permits market achieves social efficiency.

The proof is provided in the appendix so as not to disrupt the flow of the paper. This theorem lays out our main result: introducing a permits market for capital tax rate reductions induces competitive states to choose the socially efficient level of taxes so long as the number of permits is chosen correctly. A natural implication of this claim is that the sum of both states' welfare is higher under the permits market than it is in the competitive equilibrium.

Figure 1 illustrates the solution. In that figure, we have drawn each state's (inverse) demand for permits: the left $y$-axis indicates state 1's willingness to pay for each level of permit while the right $y$-axis is analogous for state 2 . The width of the $x$-axis represents the total number of 


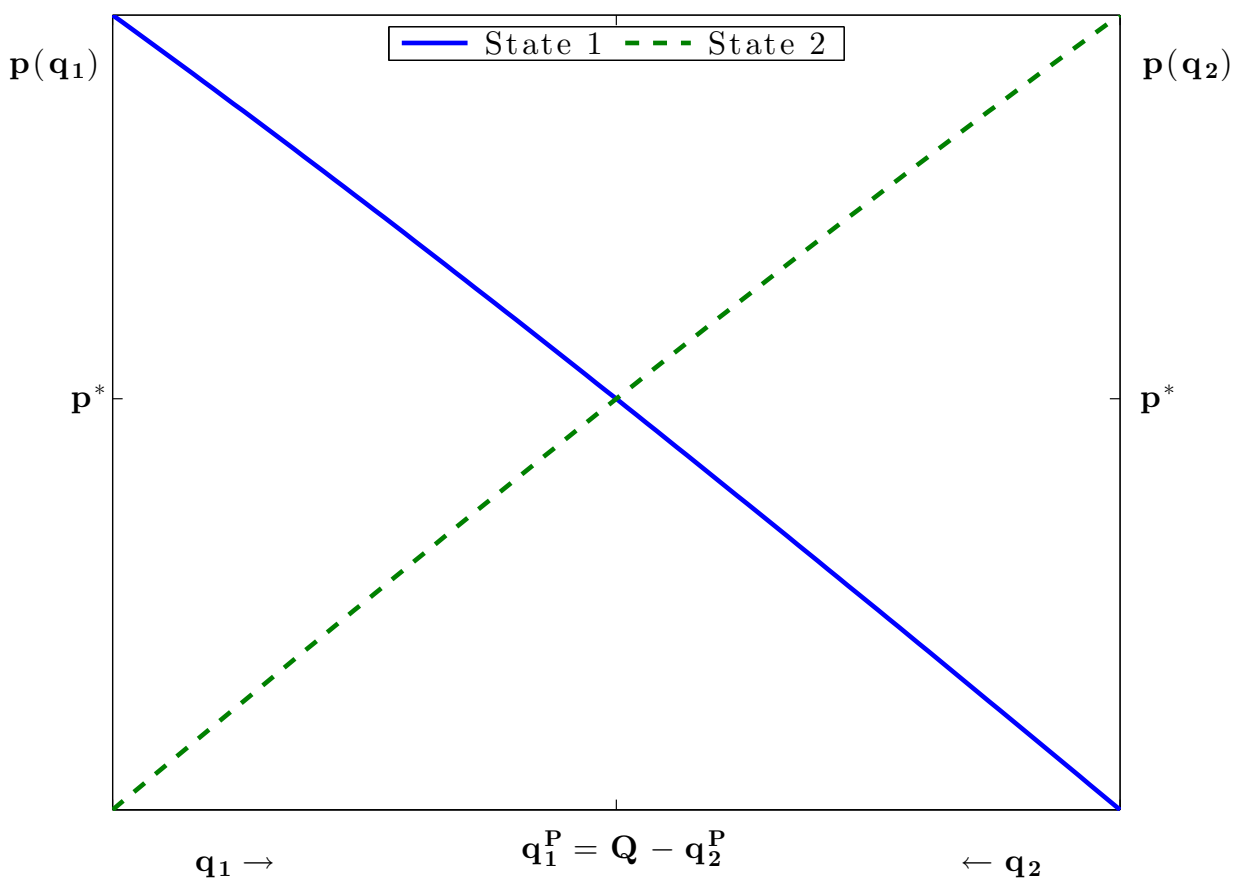

Figure 1: States' Demands for Permits and Permit Equilibrium

permits allocated by the federal government, $Q$. At quantities less (greater) than $q_{1}^{P}=Q-q_{2}^{P}$ state 1's willing to pay more (less) for additional permits than the permits are valued by state 2 ; thus, state 2 sells (buys) permits to (from) state 1. The intersection of the two curves indicates the equilibrium price for the permits - the only price at which $q_{1}+q_{2}=Q$. At this price, the marginal value of a permit is the same across both states and so there is no reason for further trade. The government's choice of $Q$ determines the width of the figure, something we return to below. Of course, the optimally-chosen number of permits implies that $\left(t_{1}^{P}, t_{2}^{P}\right)=\left(t_{1}^{F B}, t_{2}^{F B}\right)$, the same tax rates as in the first-best solution.

We have included one additional figure to help draw a comparison across the three equilibria. In Figure 2, we plot the optimal tax rates from each equilibrium for different values of $L_{1}$, holding $L_{2}$ and $k^{*}$ fixed. ${ }^{14}$ When $L_{1}=L_{2}$, we obtain the symmetric equilibria that correspond with the competitive, first-best, and permits equilibria, of the respective models presented above. It is clear

\footnotetext{
${ }^{14}$ In constructing Figure 2, we employed the quasilinear utility function $u(x, g)=\log x+g$ and the quadratic production function $f(k)=\left(\frac{3}{2}-\frac{1}{3} k\right) k$. We fixed $L_{2}$ at 1000 and allowed $L_{1}$ to vary from 400 to 2500 .
} 


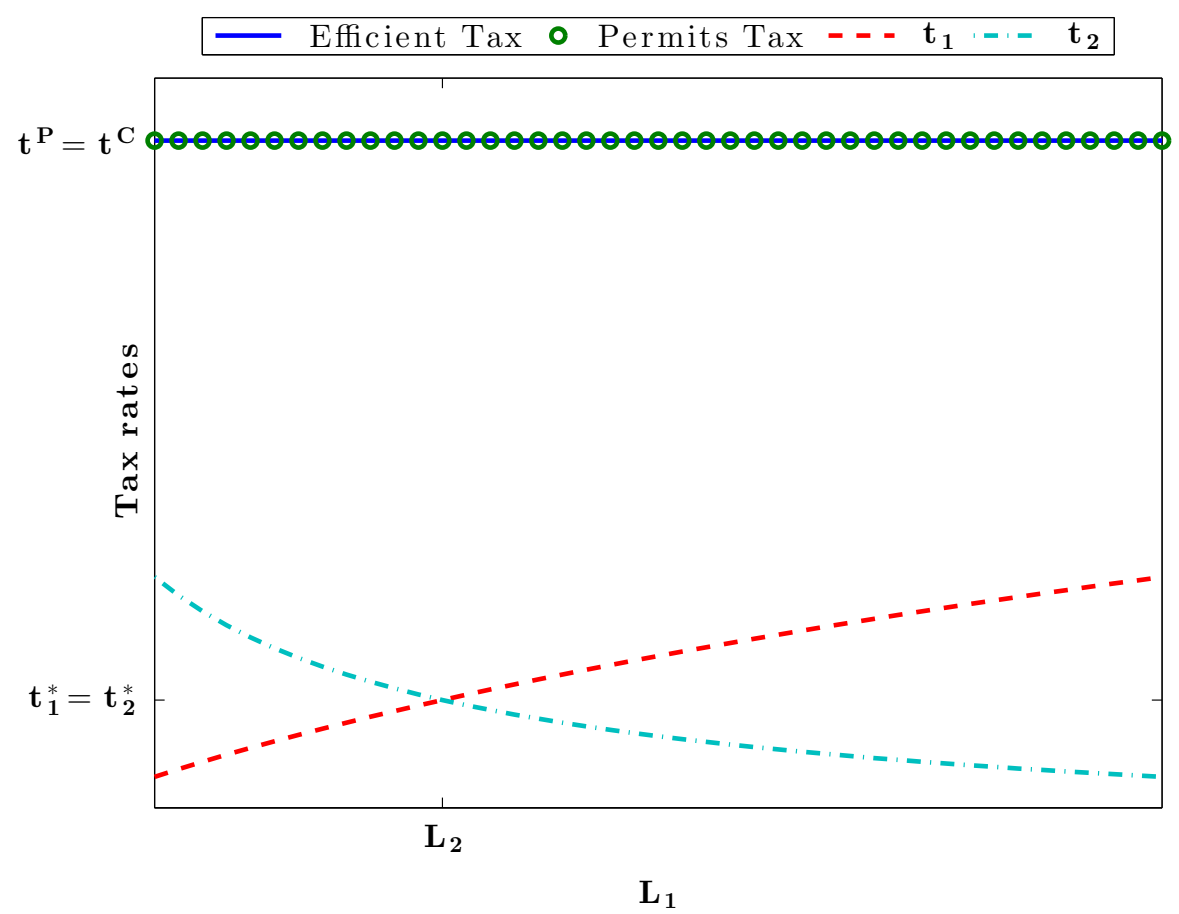

Figure 2: The Effects of Asymmetries

that in the non-cooperative, symmetric Nash equilibrium, tax harmonization obtains. As $L_{1}$ grows, the optimal tax rate in the competitive equilibrium for state 1 (2) grows (shrinks). This illustrates Lemma 2 of Wilson (1991) and Theorem 1 of Bucovetsky (1991). ${ }^{15}$ Unlike in the competitive equilibrium, as $L_{1}$ grows, the optimal tax rates in the first-best and the permits market equilibria remain constant. Regardless of the states' populations, that is, the optimal tax rates in both the first-best and the permits market equilibria are such that $t_{1}=t_{2}=t^{P}=t^{F B}$, where, for our parameterization, $t^{P}=t^{F B}$ is greater than the optimal tax rate in the competitive equilibrium. Note that $t^{P}$ (and so, of course, $t^{F B}$ too) is independent of the "size" of the asymmetry between the countries. This is because we have fixed $k^{*}$ in deriving this figure. Were we to instead fix the aggregate level of capital in the economy, then $k^{*}$ would decrease as $L_{1}$ increased, which would lead to the efficient tax rate changing with $L_{1}$. While this would change the implications suggested

\footnotetext{
${ }^{15}$ It follows, that, by Proposition 1 of Wilson (1991) and Theorem 2 of Bucovetsky (1991) the smaller state (which has the lower tax rate in equilibrium) obtains higher utility than its rival (larger) state in a competitive Nash equilibrium. This result has been extended to the general case of many states (countries) differing in their population and per capita capital endowment by Peralta and van Ypersele (2005).
} 
by this figure, it would not change the results we seek to highlight: first, that the competitive tax rates are inefficient relative to the optimal, first-best tax rate and, second, that the permits market is an effective tool in achieving efficiency.

Even though the efficient policy is optimal from a national perspective, it may not necessarily be welfare improving for each individual state -in particular, for the small state. Recall that Wilson (1991) as well as Bucovetsky (1991) characterized situations where the small state prefers the competitive Nash equilibrium to the first-best, efficient equilibrium. In light of Theorem 1, one might worry that it may then be difficult to achieve voluntary participation from all states. In spite of this, we can show the following:

Theorem 2. If the aggregate level of permits $Q$ is chosen correctly, the initial allocation of permits can be distributed in a way such that all states have incentive to participate in the permits system.

The proof is straightforward: because total welfare is higher under the permits equilibrium than it is under the competitive equilibrium, the gain in welfare can be divided up in a way that all states have incentive to join. That is, holding the value of $Q$ constant, the federal government can always allocate enough initial permits to each state such that both states are better off in the permits-regime equilibrium than in the competitive equilibrium. Theorem 2 suggests that the federal government has an additional policy tool which could help induce participation from all states: the distribution of initial permits which essentially results in utility transfers across states. Specifically, with permit sales providing a second channel of state revenue, giving one state a greater share of initial permits is a novel form of inter-governmental transfers since the permits have value in the market. The utility a state gets in the permit equilibrium is monotonically increasing in the share of permits it is initially allocated. Such utility transfers do not affect the efficiency of the permits solution, illustrating a general property of Theorem 1: regardless of the initial permit distribution, the permits equilibrium achieves the socially efficient outcome. That is, the sum of $u_{1}$ and $u_{2}$ is maximized (by definition of the federal government's problem and according to Theorem 1) regardless of how permits are allocated initially, assuming the $Q$ remains constant. Essentially, this allocation acts like lump-sum transfers from the large to small state which can be used to guarantee both states are better off in the first-best solution. Thus, the distribution of permits 
can be used to ensure all states find the permits mechanism incentive compatible since the federal government can compensate all states sufficiently well so that all prefer the permits market to the case with no regulation.

We can also state the following:

Corollary 1. If the regulatory agency chooses $Q$ inefficiently, a system of tradeable permits with competitive bidding will lead to a post-trading allocation that maximizes a population-weighted sum of states' welfare for that level of total capital tax rate reductions; i.e., no other allocation could generate more national welfare than that which obtains under a permit system in the trading equilibrium.

This result is analogous to that derived by Montgomery (1972) for a pollution permits market. Specifically, Montgomery showed permit systems will minimize the aggregate cost of achieving a given level of pollution. In our capital tax permit setting, all states reduce capital tax rates so long as the marginal benefits exceed the cost of a permit. Given that all states face the same price of a permit in equilibrium,

$$
-s_{i}\left[v^{\prime}\left(x_{i}\right) \frac{\partial x_{i}}{\partial t_{i}}+k_{i}+t_{i} \frac{\partial k_{i}}{\partial t_{i}}\right]=p
$$

for each state. That is, the marginal benefits of reducing taxes another percentage point are equated (as was shown in Figure 1) which implies that the net benefits to society from allowing a certain number of aggregate capital tax reductions (as reflected by the number of permits) are maximized in a permits equilibrium - there is no other allocation of capital tax reductions that provides society with as much benefit. Since the equation above holds in a permits equilibrium for any value of $Q$ (in Figure 1, regardless of the width of the $x$-axis), this result helps mitigate pressures to set the (perhaps uncertain) optimal number of permits in the initial instance. In fact, one possibility is that the federal government could issue the number of permits that would allow states to replicate their current (pre-mechanism) level of taxes. Permits alone hold an advantage over this competitive tax scenario in that some states may sell off permits realizing that they hold value. The federal government could then reduce the number of permits over time. This corollary shows that even for non-optimal choices of $Q$, the resulting equilibrium is constrained efficient which is an improvement 
over the competitive equilibrium.

\subsection{Discussion}

While incentive-based policies seek to internalize the externalities associated with tax competition, the decentralized nature of the capital tax permits market has numerous advantages relative to a Pigouvian tax placed on tax reductions. ${ }^{16}$ First, the permits market does not require the federal government to have large amounts of information about each state's characteristics, as does a Pigouvian tax. This is particularly valuable given that each state would have the incentive to deceive the federal government in its attempts to manipulate the Pigouvian tax it will be charged. ${ }^{17}$ Rather, for a given pair of benchmark tax rates, the federal government need only supply the correct amount of total permits to the states. Second, given an appropriate initial distribution of permits, the permits market is both individually rational and incentive compatible: states would want to join the permits mechanism and, once in, they would choose the socially efficient tax rates. Third, as Corollary 1 describes, the equilibrium in the permits market is constrained-efficient, meaning that it is still attractive even if the federal government chooses the incorrect value of $Q$. This feature is not true if the federal government chooses the wrong values of state-contingent Pigouvian taxes. As a consequence, the permits solution is in some sense more robust to mistakes by the federal government.

A potentially valuable implication of the permits market is that it gives the federal government the ability to influence the capital tax charged by the states, a power that it currently does not have. To see this, let us compare an unregulated environment with the permits alternative. In the unregulated environment, if the federal government believed that the capital tax rates charged by the states was set too low, the federal government would have no direct tool to encourage states to raise their tax rate - the federal government would take such choices as given. But, in an

\footnotetext{
${ }^{16}$ These forms of incentive-based regulation typically dominate so called command-and-control approaches such as uniform standards (a floor or ceiling imposed on the capital tax of any state), at least in terms of efficiency and, in particular, when asymmetries exist.

${ }^{17}$ The characterization of equilibria under permits (quantities) and taxes (prices) under uncertainty presented in the classic work by Weitzman (1974) provides insight into the optimal regulatory instrument to use in such settings. Interestingly, Stavins (1998, page 74) noted that "when market-based instruments have been adopted in the United States, they have virtually always taken the form of tradeable permits rather than emission taxes."
} 
environment in which the states joined the permits system, the federal government could reduce the number (cap) of initial permits distributed. This action would then lead the states to implement higher capital taxes, thus achieving what the federal government desired.

A potential disadvantage of the permits mechanism is that businesses might worry that the permits market causes increased uncertainty about tax rates. However, this issue could be addressed by increasing the length of the permit tenure. That is, permits could be redefined as the right to reduce a state's corporate income tax rate by $1 \%$ for five or even ten years. This increased tenure would have implications for the price of the permit and may allow for improved forecastability of tax rates.

With this general discussion in mind, we continue this line of reasoning by evaluating some other considerations that would allow for extensions to our core model. Our intent here is to both shed some light on how these modifications might affect our core findings as well as to provide a starting point for other researchers to continue our investigation of capital tax permits.

\subsubsection{Regional Shocks}

Permits are particularly attractive as an instrument for responding to regional shocks. To see this, consider an environment in which each state receives an idiosyncratic, privately-observed (by each respective state government) shock to its total factor productivity. Regardless of whether the shock is good or bad, a federal social planner would want to adjust its first-best capital tax rates if it could observe the state-specific shocks. Consider now the Pigouvian tax solution in which the federal government imposes state-specific taxes on all states to achieve social efficiency. In an environment with uncertainty about the state's true productive abilities, efficiency is going to be difficult to achieve unless states honestly and credibly report their idiosyncratic shocks each period. States would have incentive to lie about their shocks and a system to initiate truth-telling would need to be in place. The federal government would be charged with the difficult task of manipulating the Pigouvian rates for each state ensuring incentives are aligned every time new shocks were realized. In contrast, in the permits regime, the federal government must choose only the aggregate number of permits. That is, the federal government need only set one number, 
whereas in the Pigouvian tax setting, it must make as many choices as there are states. Admittedly, this choice is not easy, especially in light of the states holding private information. However, as Corollary 1 states, sub-optimal choices of $Q$ still lead to constrained-efficient allocations. This is because the states will continue to trade their permits until their actual marginal benefit (taking into account their private information) of reducing the capital tax rate is equal across all states. Thus, the permits solution has the advantage that the states holding the private information are induced to behave honestly and, since permits have an associated option value in the market, the states internalize all consequences of reducing capital taxes.

\subsubsection{Exogenous Price of Permits}

A concern that one might have regarding our current formulation of the permits model is the assumption that each state takes the price of the tax permits as given. For example, in the U.S., if one believes that 50 states is not sufficiently large enough to ensure that each state takes the price of a permit as given, then the states might have some market power over the price of the permits. ${ }^{18}$ If market power is a concern, what would be the resulting equilibrium in this permits system?

To consider this, assume that each state has some market power and, as such, can influence the price of the permits by altering its tax decision. This market power affects the states' incentives in two ways. First, the states that want to sell some of their initial permits would be strategic in their decision in that they would know that by accepting a higher capital tax rate, they are effectively increasing the supply of permits. As this move would reduce the market price of all permits sold, states would have the incentive to restrict the quantity of permits sold to other states. Second, the states that want to purchase permits from others would be strategic in their decision in that they would know that by purchasing an additional permit, they have effectively put upward pressure on the price of all permits bought. Knowing this, the states would have the incentive to purchase fewer permits from other states.

In this modified setup in which both sides have market power, the trading game becomes one

\footnotetext{
${ }^{18}$ In addition to the 50 states trading the permits, there is the potential for outside investors to purchase and sell the permits, as the permits are merely another type of asset that holds value to the states. Allowing investors the ability to participate in such a market would help mitigate any market power ability of a given state.
} 
of collective bargaining - in the two-state world this is like a bilateral monopoly problem. The literature on collective bargaining suggests that there is a wide range of possible equilibria in this permits game, including everything from the monopolist's equilibrium to the monopsonist's equilibrium, and importantly, the permits equilibrium described above. ${ }^{19}$ Indeed, as McDonald and Solow (1981) note, "there is a whole range of efficient bargains there is unlikely ever to be a universal agreement on the right way to do so [single one out]." Adopting an axiomatic bargaining approach, the egalitarian solution in which gains are split equally among participants, the utilitarian solution in which the sum of state welfare levels is maximized, or the Nash (1950) solution in which the product of state welfare levels is maximized, are all potential solutions to the bargaining model once permits have been allocated.

As such, while there is a continuum of possible equilibria, the actual equilibrium that results from this tax permits game depends on the states' characteristics, including their relative bargaining positions and their outside options. For example, the greater the bargaining power of the states that want to sell (purchase) the permits, the higher (lower) the equilibrium price of the permits. Or, conversely, if the states have relatively equal bargaining power, then the equilibrium price will perhaps reflect the competitive price found above. Given this, there is reason to believe that the market can be set up such that the permits equilibrium we discuss in the text will be the actual outcome. This is because the federal government can influence the states' relative bargaining positions and outside options through its choice of the distribution of initial permits. That is, the federal government could adjust the initial distribution of permits in such a way as to ensure that all states have relatively equal bargaining positions, which in turn makes the competitive equilibrium described above more likely to occur.

A second and perhaps more important reason to believe that the permits outcome will be efficient is that the permits are effectively a tool that assigns property rights. Now, with property rights assigned, the Coase Theorem applies: if the transactions costs are sufficiently small, then bargaining will result in the efficient equilibrium. This means that, while the distribution of welfare

\footnotetext{
${ }^{19}$ See, for example, Ståhl (1972), McDonald and Solow (1981), Rubinstein (1982), Myerson and Satterthwaite (1983), as well as Osborne and Rubinstein (1994) for an overview of the different approaches to modeling bargaining problems. Naturally, the timing, information structure, and preferences (risk attitudes and discount factors) are important in determining a solution.
} 
across the states might change depending on the bargaining position of the states, efficiency of the permits solution should still result.

\subsubsection{Other Fiscal Instruments}

One might wonder how capital tax permits would affect a model in which each state government has access to a richer set of tax instruments. To begin answering this, note that a robust finding of the tax competition literature is that state governments have the incentive to implement inefficient capital taxes. This finding holds across a number of different fiscal environments because each state, when deciding whether to decrease its capital tax rate, does not consider the welfare loss of other states that comes with this action. Lee (2012), for example, shows that the socially efficient capital taxes are higher than the competitive tax rates in an environment where the governments can tax both labor and capital and where the consumers have potentially heterogeneous factor endowments. Permits would be useful in this environment because they force the state governments to internalize the effect their capital tax rate choices have on other states, leading them to choose the efficient tax rates. One likely implication of this result is that there may exist spillover benefits - the state governments would be able to increase their provision of public goods while taxing labor less. Thus, we believe that the benefits of tradeable permits extend to more complex environments in which governments have access to more fiscal instruments.

\subsubsection{Innovation in the Provision of Public Goods}

Up to this point, we have assumed all governments are equally efficient. In the spirit of Besley and Case (1995), suppose this were not the case and, instead, consider a state government that innovates in the provision of the public good in a way that reduces the unit cost of providing the good to its constituents. After doing so, it will seek to reduce its capital tax rate as the state now requires lower revenues to finance its expenditures. The cheaper provision is good for society

and something the federal government wants to encourage; however, given permits are required to reduce capital tax rates, this additional cost would diminish the state's incentive to seek cheaper 
ways of providing public goods. ${ }^{20}$

Within the context of our model, we see three immediate solutions. Two are quite direct: either increase the number of permits allocated to a given (innovating) state initially or reduce the state's benchmark tax rate if it is able to improve its efficiency (as measured by the unit cost of providing public goods). For a given number of permits, a reduction in state $i$ 's benchmark tax rate $b_{i}$ will allow the firm to achieve a lower capital tax rate. The only complication here would be constructing a rule or schedule mapping cost reductions concerning provision into the benchmark tax rates. A more sophisticated permit system could allow for a third, less direct alternative. Specifically, consider something like bid preferences which are common in procurement auctions; see, for example, Hubbard and Paarsch (2009). In our setting, efficiency-improving states would be able to buy permits at discounted (preferred) prices. The federal government could subsidize the discounted price (so that the state selling permits did not receive a price that was too low). All of these would intend to preserve each state's incentive to seek better ways to provide the public good (in the spirit of "yardstick competition"), while levering the benefits of a permit system.

\subsubsection{Non-Benevolent Governments}

Thus far, we have assumed that the state governments are benevolent, maximizing their citizens' welfare. In this environment, we have shown that the introduction of capital tax permits leads the state governments to choose the socially efficient set of capital taxes. It is then interesting to explore whether tradeable permits would have the same impact on non-benevolent governments. That is, if state governments maximized some other objective function besides their citizens' welfare, would the introduction of capital tax permits lead to the socially efficient equilibrium? In the remainder of this subsection, we assume that each state government's objective is to choose the capital tax rate that maximizes its tax revenue. Just like for the benevolent governments, each Leviathan state government doesn't internalize the gain in tax revenues enjoyed by other states when it increases its capital tax. As such, the externality leads the governments to choose an inefficiently low level

\footnotetext{
${ }^{20}$ If various provision technologies were available to state governments but, perhaps adoption was costly, then the efficient tax rates would be more complex. This might be a nice way to add dynamics to the model in future work by allowing adoption choices each period. Regardless, the results of our paper should still hold-the federal government would simply be targeting a different tax rate and, as such, choosing a different aggregate level of permits $Q$.
} 
of capital taxes.

Before exploring the impact of permits, let us first understand the characteristics of the socially efficient equilibrium. This equilibrium is straightforward to characterize because, at the national level, there is a fixed amount of total capital. This implies that the capital taxes act as a lump sum tax. Consequently, in order to maximize the sum of both states' tax revenues, a social planner would raise the capital taxes as high as possible. There is, however, one constraint upon this solution: at a high enough tax rate, the consumers would choose not to invest their capital. This constraint puts an upper-bound on the capital taxes that each state can implement. Specifically, the socially efficient pair of tax rates is $t_{i}=f^{\prime}\left(k_{i}\right)$ for $i \in\{1,2\}$ which makes consumers indifferent between investing or not.

Now, given this solution, the question remains whether the introduction of capital tax permits leads the state governments to choose this efficient set of taxes. To see that it would, imagine the scenario in which the federal government gives each state just enough permits to achieve the efficient equilibrium and each state government considers setting the efficient capital tax. Would either state government like to deviate from this solution? Suppose, without loss of generality, that state $i$ chooses to purchase additional permits from state $j$. This would lead to a reduction in state $i$ 's capital tax and an increase in state $j$ 's capital tax. But, the increase in state $j$ 's tax implies that the after-tax rate-of-return on capital is negative in that state. This fact means that no consumer would invest her capital, leading the economy to produce nothing and the state government to obtain no tax revenue. Knowing this, state $j$ would never sell the additional permits to state $i$, meaning that the deviation is impossible. As a consequence, the efficient equilibrium is a Nash equilibrium when there are capital tax permits.

\section{Conclusion}

Competition for businesses to locate within state borders creates inefficiencies, if left unregulated, as the equilibrium that obtains involves all states setting inefficient capital income tax rates. Researchers have focused on tax coordination or introducing state-specific Pigouvian taxes as possible 
ways to solve this problem. The former may not be incentive compatible while the latter is information intensive for a regulator. We suggest an alternative remedy: the creation of a permits market for capital income tax reductions. The permit market establishes a cost (or opportunity cost) associated with lowering the tax rate which represents the externality states impose on rivals when making their policy choice. This solution achieves the efficient outcome, can be structured so that all states enjoy welfare gains, and induces attractive properties even if the wrong (non-first-best) level of permits is set by the federal government.

It would be interesting to consider further the various ways in which permits are initially allocated. While we have argued that efficiency can be obtained regardless of this distribution so long as the correct number of total permits is provided, the initial allocation will introduce wealth transfers across states as the establishment of a market attributes value to holding a permit. The canonical auction versus grandfather arguments can be made concerning the initial allocation. In other work (Ghosh, Hubbard, and Svec (2012)) we show how the government can use a sealed-bid auction mechanism in which the efficient level of permits is unknown to the federal government and determined endogenously, but efficiency is guaranteed if a fraction of the revenues are rebated to states as suggested by Montero (2008).

Note, too, that we followed Bucovetsky (1991) by introducing an asymmetry in the model by considering states with different populations. However, it would be instructive to consider the effects of heterogeneity along other dimensions. For example, one can imagine productivity differences across states which might obtain due to natural differences like resources or because of market forces like agglomeration effects. Likewise, it would be interesting to allow for both horizontal and vertical tax competition in the spirit of Devereux, Lockwood, and Redoano (2007). In fact, we have not discussed the use of the benchmark tax rates $b_{i}$ but because we have taken them as fixed points, they could be used to undo the welfare effects of vertical tax externalities.

In our model, we assumed that the national capital-labor ratio was fixed. In this case, the permits system only affects the distribution of capital across states and not the total amount of capital available to all states. However, it would be interesting to investigate the effects this permits mechanism has on attracting new capital (perhaps in a model with endogenous research and 
development, technological change, growth, or in a model with foreign direct investment). While our model enhances national welfare relative to the competitive equilibrium, we have admittedly considered a country in isolation. In the environmental literature, this is like correcting for local pollution, but it is possible to connect our insights with transboundary-like pollution too. If firms have the incentive to cross national borders and countries are involved in horizontal tax competition, then another layer of the model would be needed. One can imagine a global permits model (much like what is often discussed for carbon trading) in which a world planner sets permits in the way our federal planner did. Each country could then have a permit market for its subnational states in which the world permits it obtains represents the aggregate national level. Alternatively, one can imagine countries existing in an autarky-like environment with a bilateral treaty supported by trigger or tit-for-tat strategies. While beyond the scope of our paper, we feel that further investigation of these issues could be possible in a dynamic or international model and constitutes an important area for future research. We hope our framework can be easily embedded in richer models to consider such questions.

\section{References Cited}

Raymond G. Batina. Local Capital Tax Competition and Coordinated Tax Reform in an Overlapping Generations Economy. Regional Science and Urban Economics, 39(4):472-478, 2009.

Timothy Besley and Anne Case. Incumbent Behavior: Vote-Seeking, Tax-Setting, and Yardstick Competition. American Economic Review, 85(1):25-45, 1995.

Marie-Laure Breuillé. Tradable Deficit Permits: A Way to Ensure Sub-National Fiscal Discipline? EconomiX Working Papers 2007-17, University of Paris West, Nanterre la Défense, 2007.

Sam Bucovetsky. Asymmetric Tax Competition. Journal of Urban Economics, 30(2):167-181, 1991.

Roberto Cardarelli, Emmanuelle Taugourdeau, and Jean-Pierre Vidal. A Repeated Interactions Model of Tax Competition. Journal of Public Economic Theory, 4(1):19-38, 2002.

Fredrik Carlsen, Bjørg Langset, and Jørn Rattsø. The Relationship between Firm Mobility and Tax Level: Empirical Evidence of Fiscal Competition between Local Governments. Journal of Urban Economics, 58(2):273-288, 2005.

Alessandra Casella. Tradable Deficit Permits: Efficient Implementation of the Stability Pact in the European Monetary Union. Economic Policy, 14(29):321-362, 1999. 
Ronald B. Davies. State Tax Competition for Foreign Direct Investment: A Winnable War? Journal of International Economics, 67(2):498-512, 2005.

Alain de Crombrugghe and Henry Tulkens. On Pareto Improving Commodity Tax Changes under Fiscal Competition. Journal of Public Economics, 41(3):335-350, 1990.

James A. DePeter and Gordon M. Myers. Strategic Capital Tax Competition: A Pecuniary Externality and a Corrective Device. Journal of Urban Economics, 36(1):66-78, 1994.

Michael P. Devereux, Ben Lockwood, and Michela Redoano. Horizontal and vertical indirect tax competition: Theory and some evidence from the USA. Journal of Public Economics, 91(3-4): 451-479, 2007.

Michael P. Devereux, Ben Lockwood, and Michela Redoano. Do Countries Compete over Corporate Tax rates? Journal of Public Economics, 92(5-6):1210-1235, 2008.

Gagan Ghosh, Timothy P. Hubbard, and Justin Svec. Achieving Efficiency through Auctions in a Capital Tax Permits Market. Working paper, 2012.

Timothy P. Hubbard and Harry J. Paarsch. Investigating bid preferences at low-price, sealed-bid auctions with endogenous participation. International Journal of Industrial Organization, 27(1): $1-14,2009$.

Paul L. Joskow, Richard Schmalensee, and Elizabeth M. Bailey. The Market for Sulfur Dioxide Emissions. American Economic Review, 88(4):669-685, 1998.

Kangoh Lee. Why is Mobile Capital Taxed? Journal of Economics, 107(2):157-181, 2012.

Ian M. McDonald and Robert M. Solow. Wage bargaining and employment. American Economic Review, 71(5):896-908, 1981.

Enrique G. Mendoza and Linda L. Tesar. The International Ramifications of Tax Reforms: SupplySide Economics in a Global Economy. American Economic Review, 88(1):226-45, 1998.

Jack Mintz and Henry Tulkens. Commodity Tax Competition between Member States of a Federation: Equilibrium and Efficiency. Journal of Public Economics, 29(2):133-172, 1986.

Juan-Pablo Montero. A Simple Auction Mechanism for the Optimal Allocation of the Commons. American Economic Review, 98(1):496-518, 2008.

W. David Montgomery. Markets in Licenses and Efficient Pollution Control Programs. Journal of Economic Theory, 5(3):395-418, 1972.

Roger B. Myerson and Mark A. Satterthwaite. Efficient mechanisms for bilateral trading. Journal of Economic Theory, 29(2):265-281, 1983.

John F. Nash. The bargaining problem. Econometrica, 18(2):155-162, 1950.

Martin J. Osborne and Ariel Rubinstein. A Course in Game Theory. MIT Press, 1994.

Susana Peralta and Tanguy van Ypersele. Factor Endowments and Welfare Levels in an Asymmetric Tax Competition Game. Journal of Urban Economics, 57(2):258-274, 2005. 
Susana Peralta and Tanguy van Ypersele. Coordination of Capital Taxation among Asymmetric Countries. Regional Science and Urban Economics, 36(6):708-726, 2006.

Ariel Rubinstein. Perfect Equilibrium in a Bargaining Model. Econometrica, 50(1):97-109, 1982.

Joel Slemrod. Are Corporate Tax Rates, or Countries, Converging? Journal of Public Economics, 88(6):1169-1186, 2004.

Robert N. Stavins. What Can We Learn from the Grand Policy Experiment? Lessons from $\mathrm{SO}_{2}$ Allowance Trading. Journal of Economic Perspectives, 12(3):69-88, 1998.

Ingolf Ståhl. Bargaining Theory. The Economic Research Institute: Stockholm, 1972.

Tom Tietenberg. Tradeable Permits for Pollution Control when Emission Location Matters: What have we Learned? Environmental \&S Resource Economics, 5(2):95-113, 1995.

Martin L. Weitzman. Prices vs. Quantities. Review of Economic Studies, 41(4):477-91, 1974.

David E. Wildasin. Nash Equilibria in Models of Fiscal Competition. Journal of Public Economics, 35(2):229-240, 1988.

David E. Wildasin. Interjurisdictional Capital Mobility: Fiscal Externality and a Corrective Subsidy. Journal of Urban Economics, 25(2):193-212, 1989.

John Douglas Wilson. Tax Competition with Interregional Differences in Factor Endowments. Regional Science and Urban Economics, 21(3):423-451, 1991.

George R. Zodrow and Peter Mieszkowski. Pigou, Tiebout, Property Taxation, and the Underprovision of Local Public Goods. Journal of Urban Economics, 19(3):356-370, 1986.

\section{A Appendix}

Theorem 1 claims that there exists an equilibrium involving tax harmonization which is a solution to both the social planner's problem and the model with permits.

Proof. The first-order conditions characterizing the first-best solution (social planner's problem) can be expressed using the states' tax rates as decision variables as

$$
\begin{aligned}
& t_{1}: \quad s_{1} v^{\prime}\left(x_{1}\right) \frac{\partial x_{1}}{\partial t_{1}}+s_{1} \frac{\partial g_{1}}{\partial t_{1}}+s_{2} v^{\prime}\left(x_{2}\right) \frac{\partial x_{2}}{\partial t_{1}}+s_{2} \frac{\partial g_{2}}{\partial t_{1}}=0 \\
& t_{2}: \quad s_{1} v^{\prime}\left(x_{1}\right) \frac{\partial x_{1}}{\partial t_{2}}+s_{1} \frac{\partial g_{1}}{\partial t_{2}}+s_{2} v^{\prime}\left(x_{2}\right) \frac{\partial x_{2}}{\partial t_{2}}+s_{2} \frac{\partial g_{2}}{\partial t_{2}}=0
\end{aligned}
$$


Now, given our focus on an equilibrium which equalizes tax rates across states and, given the aftertax rate-of-return on capital is equal across states since capital is perfectly mobile, the solution involves capital-labor ratios being equalized. This can be seen from equation (1) and obtains because states have access to the same production functions. As such, in this equilibrium $k_{1}=k_{2}=k^{*}=k$. In particular, with quasilinear utility, $t=\frac{f(k)-\left[v^{\prime}(1)\right]^{-1}}{k}$, which is consistent with the tax rate noted in Claim 1.

Consider now the equilibrium in the permits model which is characterized by the following first-order conditions:

$$
\begin{aligned}
& v^{\prime}\left(x_{1}\right) \frac{\partial x_{1}}{\partial t_{1}}+k_{1}+t_{1} \frac{\partial k_{1}}{\partial t_{1}}+\frac{p}{s_{1}}=0 \\
& v^{\prime}\left(x_{2}\right) \frac{\partial x_{2}}{\partial t_{2}}+k_{2}+t_{2} \frac{\partial k_{2}}{\partial t_{2}}+\frac{p}{s_{2}}=0
\end{aligned}
$$

as well as the permits market-clearing condition

$$
\frac{b_{1}-t_{1}}{s_{1}}+\frac{b_{2}-t_{2}}{s_{2}}=Q
$$

In these first-order conditions, we again are assuming no terms-of-trade effects which would appear as $\partial p / \partial t_{i}$ in the first-order conditions. Using the solution from the first-best solution that $t_{1}=$ $t_{2}=t=\frac{f(k)-\left[v^{\prime}(1)\right]^{-1}}{k}$, it remains to be shown that there exists a $Q$ such that this value of $t$ is an equilibrium.

Noting that the tax rates lead to $k_{1}=k_{2}=k^{*}=k$, the above first-order conditions in a competitive model with permits become

$$
\begin{aligned}
-v^{\prime}(x) k+k+\frac{t s_{2}}{f^{\prime \prime}(k)}+\frac{p}{s_{1}} & =0 \\
-v^{\prime}(x) k+k+\frac{t s_{1}}{f^{\prime \prime}(k)}+\frac{p}{s_{2}} & =0 \\
\frac{b_{1}-t_{1}}{s_{1}}+\frac{b_{2}-t_{2}}{s_{2}} & =Q .
\end{aligned}
$$

The first two equations are redundant in that they both imply the same value of $p$ while the last 
equation can be solved for $Q$. Specifically,

$$
p=\frac{-s_{1} s_{2} t}{f^{\prime \prime}(k)}
$$

while

$$
Q=\frac{b_{1}}{s_{1}}+\frac{b_{2}}{s_{2}}-\frac{t}{s_{1} s_{2}}
$$

These terms are assured to be positive so long as the production function is strictly concave and if the benchmark tax rates exceed the (efficient) permit equilibrium tax rates, which is true by definition. Thus, the solution that solves the first-best problem is the same solution that solves the permits market for an appropriately-set level of permits. 